\title{
Módulo de reconhecimento do gênero: dissertação argumentativa do Enem sob perspectiva interacionista
}

\author{
Ana Carla Barbosa* \\ Luís Fernando Wiltemburg Santos** \\ Alessandra Dutra**** \\ Givan José Ferreira dos Santos ${ }^{* * * * *}$
}

\section{Resumo}

O estudo apresenta reflexões e possibilidades relacionadas ao módulo de reconhecimento do gênero textual na modelização didática do objeto de ensino dissertação argumentativa no ensino médio sob os moldes do gênero apreciados no Exame Nacional do Ensino Médio (Enem). Para tanto, por meio da revisão de literatura, explicita-se a presentificação do objeto de ensino, correspondente a este módulo de reconhecimento. O percurso epistemológico compreende a concepção interacionista de desenvolvimento humano mediado e observado pela linguagem, a partir dos postulados de Vygotsky e Bakhtin, do interacionismo sociodiscursivo, no que tange à transposição didática e a documentos orientadores, como a Matriz de Referência da Redação do Enem e a Cartilha do Participante. Como resultado, apresenta-se proposta metodológica produtiva para professores e estudantes do ensino médio sobre o gênero textual dissertativo-argumentativo do Enem.

Palavras-chave: Ensino. Linguagem. Português.

* Mestre em Metodologias para o Ensino de Linguagens e suas Tecnologias e bacharel em Comunicação Social - Jornalismo pela Universidade Norte do Paraná. Licenciada em Língua Portuguesa pela Universidade Tecnológica Federal do Paraná. E-mail: anacarlabarbosa.j@ gmail.com

** Licenciado em Língua Portuguesa e bacharel em Comunicação Social - Jornalismo pela Universidade Tecnológica Federal do Paraná. E-mail: luisfernandow@ gmail.com

*** Doutora em Linguística e Língua Portuguesa. Professora do Departamento de Ciências Humanas, Sociais e da Natureza da Universidade Tecnológica Federal do Paraná, Campus de Londrina. Coordenadora do Programa de Pós-Graduação em Ensino de Ciências Humanas, Sociais e da Natureza. E-mail: alessandradutra@utfpr. edu.br

***** Doutor em Estudos da Linguagem pela Universidade Estadual de Londrina. Docente do Programa de Ciências Humanas, Sociais e da Natureza da Universidade Tecnológica Federal do Paraná, Campus Londrina. E-mail: givansantos@utfpr.edu.br

Data de submissão: set. 2017 - Data de aceite: jan. 2018 http://dx.doi.org/10.5335/rdes.v14i1.7367 


\section{Introdução}

A ágil e ampla difusão de informações em todas as plataformas, sobretudo nas digitais, é uma realidade que tem trazido diversos reflexos no comportamento educacional contemporâneo. Dentre eles, está a dicotomia entre esta vasta disposição de informações aos sujeitos e, ao mesmo passo, a fragilidade de referência. É neste ponto que ações como "selecionar, relacionar, organizar e interpretar informações, fatos, opiniões e argumentos em defesa de um ponto de vista", como as preconizadas pela Matriz de Redação do Exame Nacional do Ensino Médio (Enem) (BRASIL, 2016), continuam desafiadoras para a escola, enquanto um dos principais espaços de socialização e construção do conhecimento, e para seus atores, enquanto indivíduos que enfrentam um cenário altamente competitivo no que tange aos mecanismos de avaliação.

Entende-se que a linguagem é essencial para estimular e analisar o desenvolvimento humano. Sendo assim, todas as variedades da atividade linguageira estão (ou deveriam estar) no cerne do aprimoramento escolar como contribuição para o desenvolvimento de seus atores. Nesse sentido, julgou-se tarefa essencial iniciar o trabalho a partir da reflexão sobre a relação linguagem e desenvolvimento.

É certo que tal reflexão não pode ser realizada de outro modo que não o de também buscar a transformação dos sujeitos. Por esse motivo, acredita-se ser de grande valia a intenção de descortinar os processos que podem integrar o ato de escrita da dissertação argumentativa, objeto de estudo em questão. Nesse contexto, propor a leitura e a análise das dimensões presentes no gênero de texto é uma estratégia com grande potencial para se estimular a construção de repertórios críticos e, consequentemente, subsidiar a redação, afinal, entende-se que leitura e escrita estão sempre associadas nos processos de autoria, porque, obviamente, pressupõem internalizações e externalizações ou, ainda, internalizações e recriações dos mais variados discursos. Portanto, trata-se não apenas de atentar para os aspectos normativos do gênero, mas de entender que forma e conteúdo não são categorias isoladas, antes, complementam-se dialogicamente neste processo que conjuga a subjetividade e, ao mesmo passo, não deixa de reproduzir o que é tácito numa interação comparada à "repetição com criação". O novo se produz na base do velho, o "dado" se transforma em "criado" (BAKHTIN, 2010).

Em consonância com as proposições discorridas até aqui, o objetivo primordial deste artigo é apresentar reflexões e encaminhamentos didáticos, na ótica interacionista, a respeito do módulo de reconhecimento do gênero textual dissertativo-argumentativo solicitado para produção no Enem. O itinerário da pesquisa primeiramente percorre, dadas as possibilidades do recorte, a síntese da ideia vygotskyana de desenvolvimento 
humano, da qual decorre a teoria histórico-cultural; em segundo, as contribuições de Bakhtin (1997) acerca do papel da linguagem neste desenvolvimento, bem como explanações do interacionismo sociodiscursivo quanto aos gêneros de texto, além da Matriz de Redação do Enem no que diz respeito ao gênero dissertação argumentativa. Já a segunda parte do estudo comporta uma proposta didática voltada especificamente ao módulo de apresentação do gênero (COSTA-HÜBES; SIMIONI, 2014), por se acreditar que tal adaptação da modelização didática proposta pela escola genebrina é fundamental para o contexto escolar brasileiro, além de se tratar diretamente da presentificação do objeto de ensino, entendida, sob o viés de Nascimento e Brun (2017), como o gesto profissional do professor de apresentar este objeto por meio de comandos de trabalho.

\section{Linguagem e desenvolvimento}

É sempre importante salientar que não cabe à pesquisa a tarefa vazia de desqualificar determinada perspectiva teórica e metodológica em relação à outra. Acredita-se na complementaridade de ideias e nas escolhas conscientes diante de propósitos específicos. Por esse motivo, julga-se pertinente a concepção vygotskyana de desenvolvimento humano por se priorizar sua característica interacionista. Embora as obras mais significativas de Lev Vygotsky datem do início do século XX, seu legado é bastante contemporâneo, devido à sua característica interdisciplinar. Oliveira descreve as contribuições do intelectual russo como

[...] a tentativa de reunir, num mesmo modelo explicativo, tanto os mecanismos cerebrais subjacentes ao funcionamento psicológico, como o desenvolvimento do indivíduo e da espécie humana, ao longo de um processo sócio-histórico [sic] (1993, p. 14).

Daí a ideia do ser humano em um processo histórico e a ênfase em suas transformações explicada na síntese de processos psicológicos.

A autora ainda esclarece que o termo síntese carece de atenção quando presente neste contexto, pois pressupõe a síntese entre dois elementos da Psicologia, quando Vygotsky se debruçou em proporcionar uma nova perspectiva para esta ciência, que, até então, era prioritariamente observada ou como ciência mental ou como ciência filosófica. Síntese, para Vygotsky, "não é a soma ou justaposição desses dois elementos, mas a emergência de algo novo, anteriormente inexistente" (OLIVEIRA, 1993, p. 23).

\footnotetext{
Esse componente novo não estava presente nos elementos iniciais: foi tornado possível pela interação entre esses elementos, num processo de transformação que gera novos fenômenos. Assim, a abordagem que busca uma síntese para a Psicologia integra, numa mesma perspectiva, o homem enquanto corpo e mente, enquanto ser biológico e ser social, enquanto membro da espécie humana e participante de um processo histórico (OLIVEIRA, 1993, p. 23).
}

Desta premissa, é possível pontuar três pilares básicos do pensamento vygotskyano descritos por Oliveira (1993): $1^{\mathrm{o}}$ 
- as funções psicológicas têm um suporte biológico, pois são produtos da atividade cerebral; $2^{\mathrm{o}}$ - o funcionamento psicológico fundamenta-se nas relações sociais entre o indivíduo e o mundo exterior, as quais desenvolvem-se num processo histórico; $3^{\text {o }}$ - a relação homem/mundo é mediada por sistemas simbólicos.

Ainda, de acordo com a autora, é preciso aclarar algumas considerações sobre estes pontos. $\mathrm{O}$ primeiro depreende que o cérebro, como órgão material, é a base biológica do funcionamento psicológico. Esta existência material é que define os limites e as possibilidades do desenvolvimento, porém, o cérebro não deve ser visto como um sistema de funções imutáveis, mas como uma materialidade plástica, moldada ao longo da história pelo desenvolvimento da espécie e individual (OLIVEIRA, 1993, p. 24). Por sua vez, o segundo ponto pode ser resumido na seguinte afirmação de Oliveira: "o homem transforma-se de biológico para sócio-histórico, num processo em que a cultura é parte essencial da constituição da natureza humana" (1993, p. 24). É esta característica que prioritariamente difere a abordagem histórico-cultural de uma abordagem cognitivista de desenvolvimento. Na primeira perspectiva, o desenvolvimento psicológico não é abstrato ou isolado/descontextualizado, mas as chamadas funções psíquicas superiores (sensação, percepção, atenção, memória e linguagem) são baseadas nos modos culturalmente constituídos de ordenar o real (OLIVEIRA, 1993).
Sendo assim, é natural que se integre ao terceiro ponto o conceito de mediação:

A relação do homem com o mundo não é uma relação direta, mas uma relação mediada, sendo os sistemas simbólicos os elementos intermediários entre o sujeito e o mundo (OLIVEIRA, 1993, p. 24).

Vale ressaltar que, a partir desta progressão explicativa, é possível detectar com mais clareza as convergências dos postulados de Vygotsky com o pensamento marxiano. Primeiro, faz-se necessário debruçar-se sobre essa constatação porque, para se entender o conceito de mediação por meio de instrumentos $\mathrm{e}$ signos, é preciso compreender o que são instrumentos nesta concepção e, para tanto, precisa-se compreender também o papel do trabalho no desenvolvimento social.

Vygotsky busca compreender as características do homem através do estudo da origem do desenvolvimento da espécie humana tomando o surgimento do trabalho e a formação da sociedade humana com base no trabalho, como sendo o processo básico que vai marcar o homem como espécie diferenciada (OLIVEIRA, 1993, p. 27).

Vê-se, então, que o instrumento é o elemento interposto entre o trabalhador e o objeto de seu trabalho. Ele atende a um objetivo e traz intrinsecamente a função para a qual foi criado e o modo de utilização desenvolvido historicamente pelo coletivo de trabalho. "É, pois, um objeto social e mediador da relação entre o indivíduo e o mundo" (OLIVEIRA, 1993, p. 29).

Situada a ideia de instrumento, atenta-se para o papel dos signos na me- 
diação. Semelhantemente à função dos instrumentos, os signos também agem como meios auxiliares, mas no campo psicológico. De acordo com Oliveira,

[...] os signos são interpretáveis como representação da realidade e podem referir-se a elementos ausentes do espaço e do tempo presentes [...] São os elementos que representam ou expressam outros objetos, eventos, situações (1993, p. 30).

Para explicar as formas mais elevadas do comportamento humano, temos que pôr a nu os meios através dos quais o homem aprende a organizar e dirigir o seu comportamento. Todas as funções psíquicas de grau mais elevado são processos mediados e os signos são os meios fundamentais utilizados para os dominar e orientar. O signo mediador é incorporado na sua estrutura como parte indispensável a bem dizer fulcral do processo total. Na gênese do conceito, esse signo é a palavra, que a princípio desempenha o papel de meio de formação de um conceito, transformando-se mais tarde em símbolo (VYGOTSKY, 2001, não paginado).

$\mathrm{Na}$ ausência de um sistema de signos, linguísticos ou não, só é possível o mais primitivo e limitado tipo de comunicação (VYGOTSKY, 2001, não paginado).

\section{Vygotsky complementa que}

[...] a transmissão racional, intencional de experiências e de pensamentos a outrem exige um sistema mediador, que tem por protótipo a linguagem humana nascida da necessidade do intercâmbio durante o trabalho (2001, não paginado, grifo nosso).

Em resumo, os significados só são possíveis pelo fenômeno do pensamento verbal ou da fala significante - união do pensamento e da linguagem.

Não é novidade que os postulados do autor permitem uma vasta investigação sob diversos prismas para se analisar o desenvolvimento humano, contudo, esta breve revisão tem a linguagem por palavra-chave e, por esse motivo, avança para percepções teórico-práticas que dela derivam, como a bakhtiniana.

Bakhtin concorda que as relações interativas são processos produtivos de linguagem e muito acrescenta ao debate ao desenvolver sua teoria dos gêneros, que considera o dialogismo do processo comunicativo em vez de priorizar uma classificação de espécies dos gêneros do discurso. Os gêneros passam a ser focalizados como esferas dos usos de linguagem verbal ou da comunicação fundada na palavra (MACHADO, 2005). Esta visão é muito relevante para os estudos da linguagem, pois vai além da tradição retórica e agrega as práticas prosaicas.

Porque é discurso, a prosa só existe na interação. Não se constitui a partir de nenhuma estrutura formular, mas tão somente em discursos (MACHADO, 2005, p. 154).

Trata-se de um processo, não de substituição de uma forma discursiva por outra e de consequente polaridade, mas de evolução das próprias práticas significantes de sistemas comunicativos que emergem das situações dialógicas, ainda que cada uma delas tenha o seu campo de significação muito preciso (MACHADO, 2005, p. 154).

O processo a que Machado (2005) se refere corresponde às diferentes esferas dos usos de linguagem, às práticas significantes emergentes ao "universo do discurso", em outros termos, aos gêneros do discurso e sua decorrente organização em textos. Bakhtin afirma que: 
[...] a riqueza e a variedade dos gêneros do discurso são infinitas, pois a variedade virtual da atividade humana é inesgotável, e cada esfera dessa atividade comporta um repertório de gêneros do discurso que vai diferenciando-se e ampliando-se à medida que a própria esfera se desenvolve e fica mais complexa (1997, p. 279).

Sobre a questão, Machado elucida que, "do ponto de vista do dialogismo, porém, a prosaica é a esfera mais ampla das formas culturais no interior das quais outras esferas são experimentadas" (2005, p. 155). Esta constatação leva à distinção que Bakhtin (1997) realiza entre os gêneros discursivos primários e secundários. São considerados primários os gêneros da comunicação cotidiana e, secundários, os gêneros oriundos da comunicação produzida a partir de códigos culturais elaborados, como a escrita (MACHADO, 2005). Vale ressaltar que ambos os gêneros não ocupam posições refratárias, mas se complementam e se modificam mediante o contato das esferas dos usos de linguagem. Esta interação se refere aos enunciados concretos.

As esferas do uso de linguagem não são uma noção abstrata, mas uma referência direta aos enunciados concretos que se manifestam nos discursos (MACHADO, 2005, p. 156).

Todas as manifestações verbais mediante a língua se dão como textos e não como elementos linguísticos isolados. Esses textos são enunciados no plano das ações sociais situadas e históricas. Bakhtinianamente falando, toda a manifestação linguística se dá como discurso, isto é, uma totalidade viva e concreta da língua não como abstração formal [...] O enunciado ou discurso não é um ato isolado e solitário, nem da oralidade, nem na escrita (MARCUSCHI, 2011, p. 20).
A explanação de Marcuschi (2011) encontra-se com as apropriações do interacionismo sociodiscursivo frente ao pensamento bakhtiniano. É interessante retomar, ainda que sucintamente, um pressuposto fundamental desta escola no que tange aos gêneros secundários do discurso, mais especificamente, aos gêneros de texto, como se prefere nomear aqui. Bronckart (2006) pontua que a realização dessa atividade/ação de linguagem se dá por meio de textos que podem ser entendidos como a materialização linguística das atividades de linguagem de um determinado grupo e um texto que corresponderia, por sua vez, à materialização linguística de uma ação de linguagem. Na mesma linha, Nascimento e Pereira afirmam que,

[...] em uma perspectiva vygotskiana, os gêneros textuais tornam-se instrumentos que medeiam aprendizagens que têm como foco o desenvolvimento do aluno em várias situações sociais (2014, p. 98).

É a partir desta reflexão que se abre caminho para o foco deste recorte: a linguagem no âmbito do ensino. Costa-Hübes e Simioni enfatizam que a adoção de um ensino da língua, partindo do pressuposto da interação verbal para direcionar o trabalho com gêneros, exige, antes, que se reflita sobre metodologias que contemplem uma concepção sociointeracionista em que a língua é percebida como "algo que permeia o cotidiano, articulando nossas relações com o mundo e com os outros" (COSTA-HÜBES; SIMIONI, 2014, p. 16). É com esta preocupação que a próxima seção é apresentada. 


\section{Dissertação argumentativa no Enem e presentificação}

Reconhecida a diversidade dos gêneros textuais, é preciso reconhecer também o desafio de "aprender a ler lendo todos os tipos de texto" (DOLZ, 2014, p. 1). Atenta-se para o termo leitura porque, como já dito anteriormente, entende-se que, no objetivo de ensino da escrita de um determinado gênero, a leitura é uma capacidade que deve ser desenvolvida conjuntamente. Ademais, Dolz (2014) reforça que ler e escrever sempre deverão ser as prioridades da escola. Ler e escrever são duas aprendizagens essenciais de todo o sistema da instrução. Um cidadão que não tenha essas duas habilidades está condenado ao fracasso escolar e à exclusão social (DOLZ, 2014, p. 1).

Do ponto de vista social, a escrita permite $o$ acesso às formas de socialização mais complexas da vida cidadã. Mesmo que os alunos não almejem ou não se tornem, no futuro, jornalistas, políticos, advogados, professores ou publicitários, é muito importante que saibam escrever diferentes gêneros textuais, adaptando-se às exigências de cada esfera de trabalho (DOLZ, 2014, p. 1).

Sob esta lógica, chama-se a atenção para o gênero dissertação argumentativa, prescrito no Enem. Atualmente, o gênero solicitado na prova de redação do exame é um dos mais relevantes objetos de ensino da escrita nas escolas brasileiras, pois, além de compor os mecanismos de avaliação do ensino nacional, está intimamente associado às capacidades presentes em outros gêneros textuais previstos no nível médio, como o artigo de opinião. A dissertação argumentativa também elenca características comuns e fundamentais da materialidade discursiva cotidiana, a exemplo do posicionamento crítico do interlocutor e sua habilidade persuasiva, todavia, a descrição do gênero será melhor conduzida tendo por referência a própria Cartilha do Participante do Enem, elaborada e disponibilizada pelo Instituto Nacional de Estudos e Pesquisas Educacionais Anísio Teixeira (Inep), ligado à Diretoria de Avaliação da Educação Básica (Daeb) do Ministério da Educação (MEC). O documento é datado de setembro de 2016 e define que:

O texto dissertativo-argumentativo é um texto que se organiza na defesa de um ponto de vista sobre determinado assunto. É fundamentado com argumentos, para influenciar a opinião do leitor ou ouvinte, tentando convencê-lo de que a ideia defendida está correta. É preciso, portanto, expor e explicar ideias. Daí sua dupla natureza: é argumentativo porque defende uma tese, uma opinião, e é dissertativo porque são utilizadas explicações para justificá-la. Seu objetivo é, em última análise, convencer ou tentar convencer o leitor pela apresentação de razões e pela evidência de provas, à luz de um raciocínio coerente e consistente (BRASIL, 2016, p. 19).

Cabe também expor as exigências de elaboração do gênero trazidas pela Cartilha do Participante, conforme se observa no Quadro 1: 
Quadro 1 - Quadro explicativo de exigências de elaboração do texto dissertativo-argumentativo da Redação do Enem 2016

\begin{tabular}{|c|c|}
\hline $\begin{array}{l}\text { - Apresentar uma tese, desenvolver } \\
\text { justificativas para comprová-la } \\
\text { e uma conclusão elaborada no } \\
\text { texto, compondo o processo argu- } \\
\text { mentativo. }\end{array}$ & $\begin{array}{l}\text { TESE - É a ideia que você vai defender no seu texto. Ela deve estar } \\
\text { relacionada ao tema e deve estar apoiada em argumentos ao longo } \\
\text { da redação. } \\
\text { ARGUMENTOS - É a justificativa para convencer o leitor a con- } \\
\text { cordar com a tese defendida. Cada argumento deve responder à } \\
\text { pergunta "por que?" em relação à tese defendida. }\end{array}$ \\
\hline $\begin{array}{l}\text { - Utilizar estratégias argumentativas } \\
\text { para expor o problema discutindo } \\
\text { no texto e detalhar os argumentos } \\
\text { utilizados. }\end{array}$ & $\begin{array}{l}\text { ESTRATÉGIAS ARGUMENTATIVAS - São recursos utilizados para } \\
\text { desenvolver os argumentos, de modo a convencer o leitor: } \\
\text { - exemplos; } \\
\text { - dados estatísticos; } \\
\text { - pesquisas; } \\
\text { - fatos comprováveis; } \\
\text { - citações ou depoimentos de pessoas especializadas no assunto; } \\
\text { - pequenas narrativas ilustrativas; } \\
\text { - alusões históricas; e } \\
\text { - comparações entre fatos, situações, épocas ou lugares distintos. }\end{array}$ \\
\hline
\end{tabular}

Fonte: Brasil (2016).

Como explicita a referência, o gênero tem por principais características a argumentação e sua intenção de persuadir o leitor, portanto, é prioritariamente opinativo e dialógico. Estas características são refletidas mais especificamente nas competências II, III e V avaliadas pela Matriz de Redação do Enem:

I- Demonstrar domínio da norma padrão da língua escrita.

II- Compreender a proposta de redação e aplicar conceitos das várias áreas de conhecimento para desenvolver o tema, dentro dos limites estruturais do texto dissertativo-argumentativo.

III- Selecionar, relacionar, organizar e interpretar informações, fatos, opiniões e argumentos em defesa de um ponto de vista.

IV- Demonstrar conhecimento dos mecanismos linguísticos necessários para a construção da argumentação.
V- Elaborar proposta de solução para o problema abordado, respeitando os valores humanos e considerando a diversidade sociocultural (BRASIL, 2011, não paginado).

Notadamente, o desafio para o ensino e, consequentemente, para a autoria da dissertação argumentativa do Enem se centra em promover estratégias que conjuguem a dimensão estrutural (ou normativa) com a dimensão crítica inerente ao gênero. É neste aspecto que se retoma a reflexão inicial deste tópico: "leitura e escrita como prioridades da escola". Leitura, porque, no processo de desenvolvimento, ela é compreendida como um mecanismo interpretativo, um dispositivo para internalização do que de fato o sujeito apreende do mundo que o rodeia; escrita, porque, nesse contexto, ela é a linguagem que medeia a represen- 
tação/externalização da síntese desta(s) leitura(s).

Tendo em vista a cartilha, este processo é traduzido em uma espécie de "equação" para orientar a atividade de escrita. Alguns exemplos de leitura e composição de repertório interpretativo são denominados pela cartilha de "estratégias argumentativas" e orientam a fundamentação da dissertação amparada por "exemplos, dados estatísticos, pesquisas, fatos comprováveis, pequenas narrativas ilustrativas, alusões históricas", entre outros termos. Logo se vê que o comando I de elaboração do texto - "apresentar uma tese, desenvolver justificativas para comprová-la e uma conclusão que dê fecho à discussão elaborada no texto, compondo o processo argumentativo" - implica prioritariamente a dimensão subjetiva da autoria. O que a cartilha diz, em essência, é que não basta ao participante identificar ou enumerar argumentos. É preciso interpretá-los, relacioná-los, desenvolvê-los, tarefas estas que só são possíveis com o desenvolvimento da capacidade de leitura em seu mais amplo sentido.

Também não se ignoram o reconhecimento da complexidade do gênero e a necessidade de uma sequência didática que aprecie o todo de suas dimensões discursivas e textuais, contudo, o presente recorte aponta para o desenvolvimento de um módulo que apresenta aspectos básicos da dissertação argumentativa do Enem, do qual se destacam alguns objetivos, tais como fazer o estudante conhecer a formatação lógica da prova de redação do Enem e exemplificar a leitura crítica de outros gêneros, a fim de compor o repertório de estratégias argumentativas a ser empregado pelo aluno. Este módulo de apresentação é responsável pela presentificação do objeto de ensino.

Aeby-Daghé e Dolz (2008 apud NASCIMENTO; BRUN, 2017) explicam que, diante da transposição didática, são identificados gestos profissionais do professor. Dentre esses gestos, destaca-se o de presentificação, que tem por finalidades mostrar aos alunos o objeto de ensino com os suportes adequados e apresentar os objetos do saber que passarão por processos de didatizatização por meio de dispositivos adequados. Esse gesto também se relaciona ao de formulação de tarefas, que

[...] possibilita a entrada do objeto no dispositivo didático, por esse gesto o professor apresenta consignas/comandos de trabalho pelos quais o objeto é presentificado (NASCIMENTO; BRUN, 2017, p. 6).

Ainda conforme Nascimento e Brun (2017), o gesto de formular tarefas é responsável por introduzir os dispositivos didáticos por meio da formulação de comandos/consignas do professor.

\section{Apresentar e refletir: atividades básicas antes da produção inicial}

Os encadeamentos de atividades propostos a seguir não contemplam integralmente a modelização do gênero 
por meio de sequência didática prevista pelo Grupo de Genebra, cujo esquema é representado na Figura 1, mas se concentra em uma etapa específica, o módulo de apresentação do gênero, fruto de uma adaptação que será comentada mais adiante. A estrutura do modelo genebrino vai desde a apresentação inicial da situação, o que Costa-Hübes e Simioni avaliam como "apresentar ao aluno uma situação concreta de uso da linguagem e a necessidade de se produzir um texto de determinado gênero para atender a esta situação" (2014, p. 24), até a produção final.

Figura 1 - Esquema de sequência didática conforme o grupo de pesquisadores de Genebra
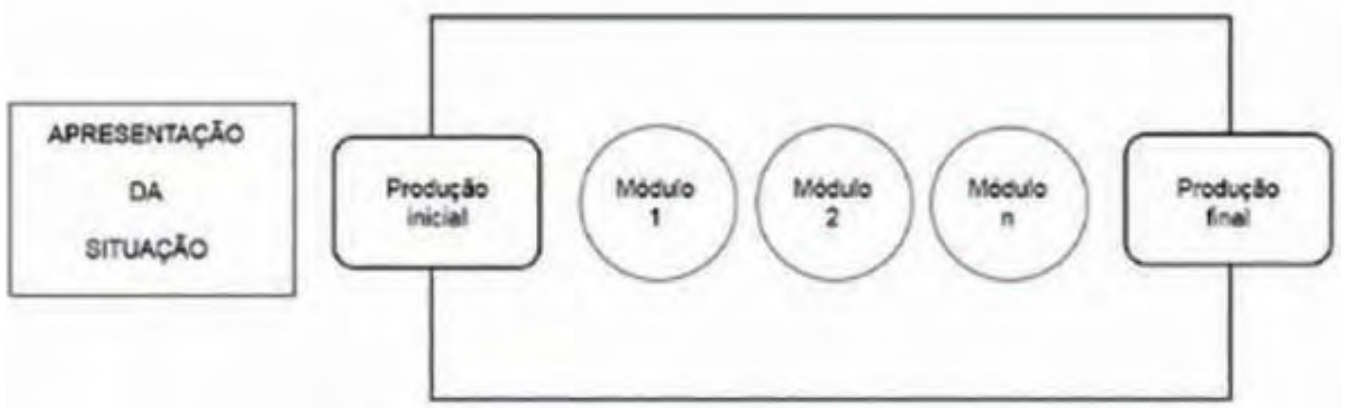

Fonte: Dolz, Noverraz e Schneuwly (2004).

Neste contexto, a situação concreta de uso da linguagem correspondente ao gênero dissertação argumentativa se relaciona à prova de redação do Enem, que, além de compor um mecanismo nacional de avaliação do ensino básico brasileiro, é uma das etapas obrigatórias para o estudante que deseja cursar o ensino superior em uma universidade pública federal por meio do Sistema de Seleção Unificada (Sisu) ou em outras instituições que agreguem o Enem em seus processos seletivos.

Dada a relevância de tal contexto de produção, julgou-se pertinente concentrar esforços na sugestão de reconhecimento do gênero atrelada à apresentação inicial da situação de comunicação, equivalente à adaptação da sequência didática formulada por Costa-Hübes e Swiderski (2009), que prevê o acréscimo de um módulo de reconhecimento anterior à produção inicial. Este módulo de reconhecimento configura um momento decisivo para a condução de todo o trabalho do professor e do estudante com o gênero textual. Em resumo, trata-se de uma série de ações que permitam um melhor reconhecimento do gênero antes que seja solicitada uma produção textual ao aluno. É importante explicar o motivo de não se optar pelo encadeamento previsto pela escola genebrina: 
Uma vez que os alunos brasileiros estão inseridos em um sistema de ensino que não privilegia aulas de produção textual do mesmo modo que a Suíça, o acréscimo do módulo de reconhecimento do gênero antes da produção inicial tem como finalidade desenvolver, com os alunos, atividades que contemplam a pesquisa, a leitura e a análise linguística de textos do gênero em estudo, recorrendo, para isto, àqueles que já circulam socialmente (COSTA-HÜBES; SIMIONI, 2014, p. 26, grifo das autoras).

A representação da estrutura de base da adaptação realizada por Costa-Hübes pode ser conferida conforme Figura 2:

Figura 2 - Esquema de sequência didática adaptada por Costa-Hübes

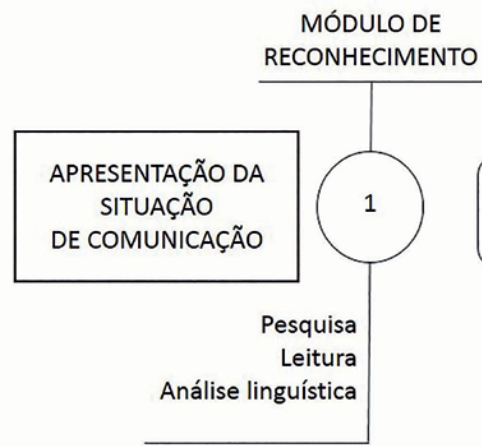

Fonte: Costa-Hübes e Swiderski (2009).

Vale salientar que a escolha por esta adaptação também permite explorar a própria Cartilha do Participante do Enem, cuja seção 2 - "Amostra de redações nota 1.000 " - comporta comentários sobre os textos escritos por participantes do exame em 2015. Esta proposta de atividade tem o intuito de demonstrar as referências de argumentação e fundamentação utilizadas pelo autor da redações comentadas pela cartilha, a fim de proporcionar o reconhecimento do gênero, o que reflete o objetivo de projetar leituras e possibilidades para a constituição de estratégias argumentativas, pois se acredita que a validação de uma sequência que contemple desde a apresentação inicial até a produção escrita final necessitaria de uma análise comparativa após a testagem do instrumento em sala de aula, ação que este recorte de pesquisa não abarca por ora.

\section{Apresentação do gênero}

O professor deve realizar uma apresentação que remeta à situação concreta de uso da linguagem (ou de uso de comunicação), o que já foi descrito na seção anterior, neste caso, a própria realização da prova de redação do Enem. Porém, mesmo diante do apelo da prova, pois os estudantes do ensino 
médio direcionam boa parte de seus estudos ao exame, é necessário acrescentar outros elementos que possam instigar a curiosidade dos estudantes sobre a escrita da dissertação. Este passo é fundamental porque será responsável pela motivação de todas as etapas que compõem o módulo de reconhecimento, que são reconhecimento do gênero, pesquisa, leitura de textos do gênero e análise linguística (COSTA-HÜBES; SIMIONI, 2014).

\section{Questionar para presentificar}

A sugestão de apresentação inicial do gênero consiste na projeção de um gráfico. A projeção apresenta a classificação percentual das notas de redação dos candidatos do Enem 2015 divulgada pelo Inep em 2016, todavia, a fonte dos dados não deve ser esclarecida pelo professor em um primeiro momento. Antes, ele deve perguntar à turma qual a suposição dela sobre a origem do gráfico (Figura 3):

Figura 3 - Percentual de médias obtidas pelos candidatos na prova de redação do Enem 2015

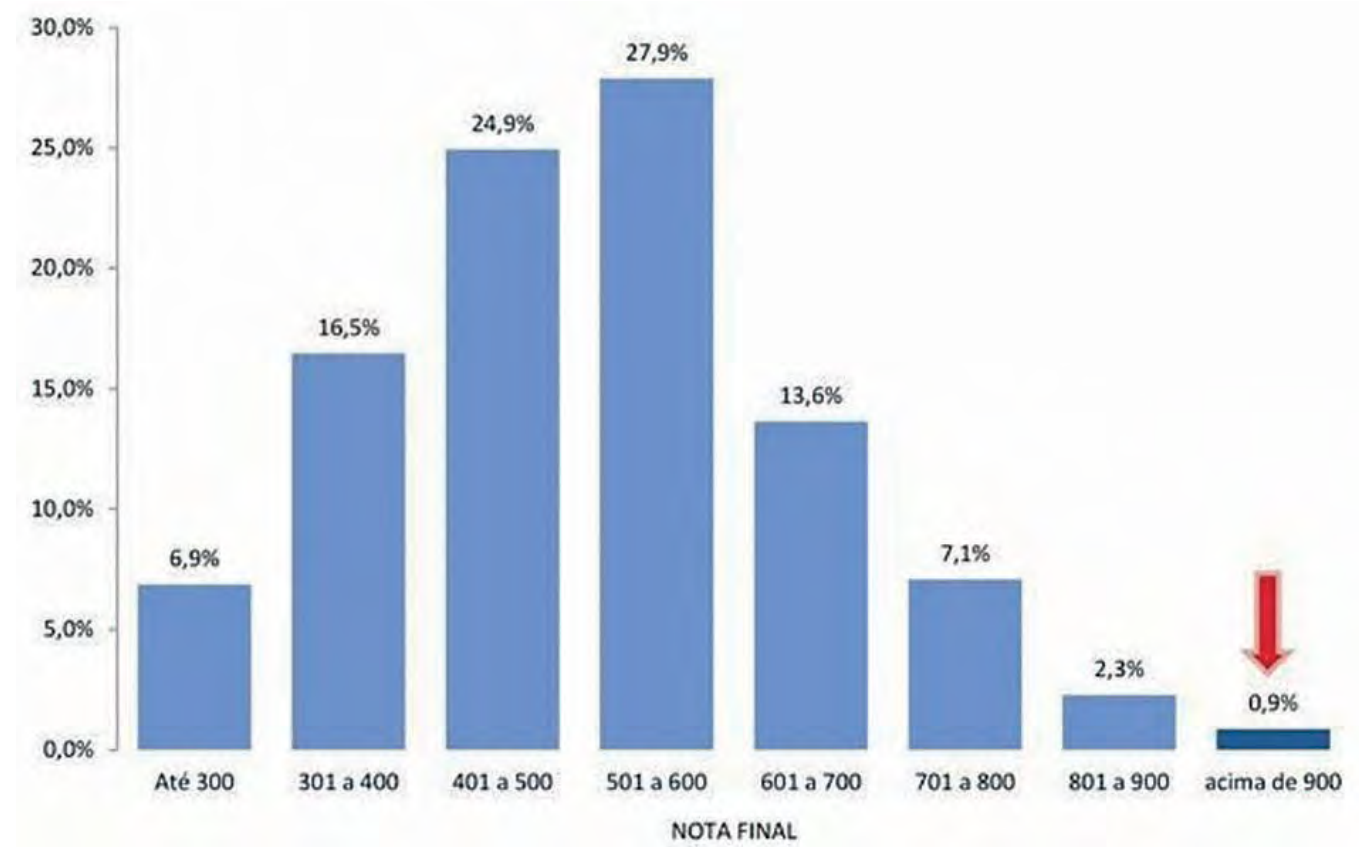

Fonte: Brasil (2016).

É importante que as perguntas sejam feitas de modo descontraído, como: "Alguém imagina sobre o que estes índices tratam?”; “Quem arrisca um palpite sobre estes números?"; "Você gostaria de estar classificado em algum destes índices?". Também é relevante que o professor desenvolva as possíveis respostas dos alunos 
antes de explicar a fonte dos índices. Ao revelar a origem da informação, é necessário atentar para a média destacada: apenas 0,9 dos redatores de 2015 obtiveram nota acima de 900 . Este dado conduz aos próximos questionamentos do professor: "Por que o número de candidatos com média acima de 900 é tão baixo em relação às outras médias?"; "O que você acredita que uma redação nota 1.000 precisa ter?".
Ao se debater sobre o que uma redação nota 1.000 "precisa ter", é aberto caminho para a segunda etapa do módulo da apresentação, que é o reconhecimento do gênero. A pergunta "Você já leu uma dissertação do Enem?" precede a projeção de outra imagem, um espelho da folha de transcrição acompanhado da prova de redação do Enem 2015 (Figuras 4 e 5 ).

Figura 4 - Espelho de redação do Enem 2015 com nota 940

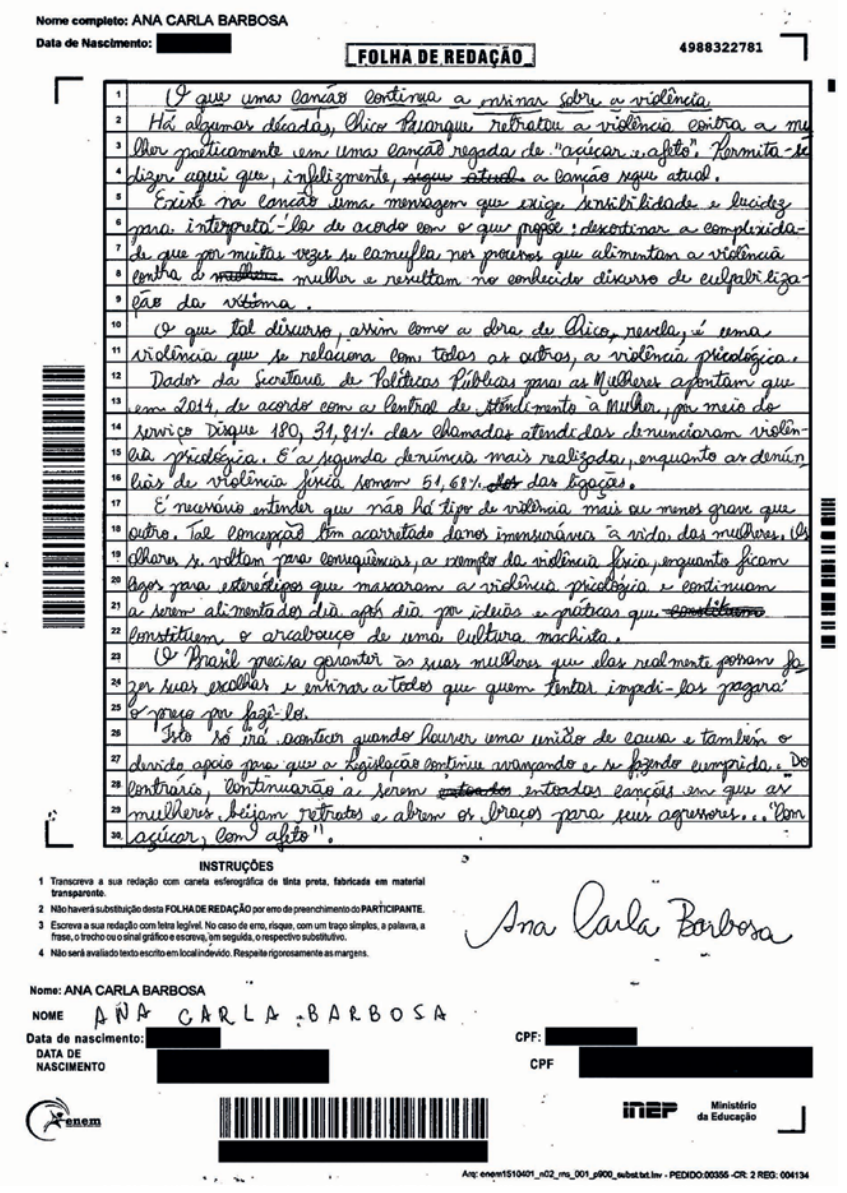

Fonte: Brasil (2016). 
Figura 5 - Prova de redação do Enem 2015

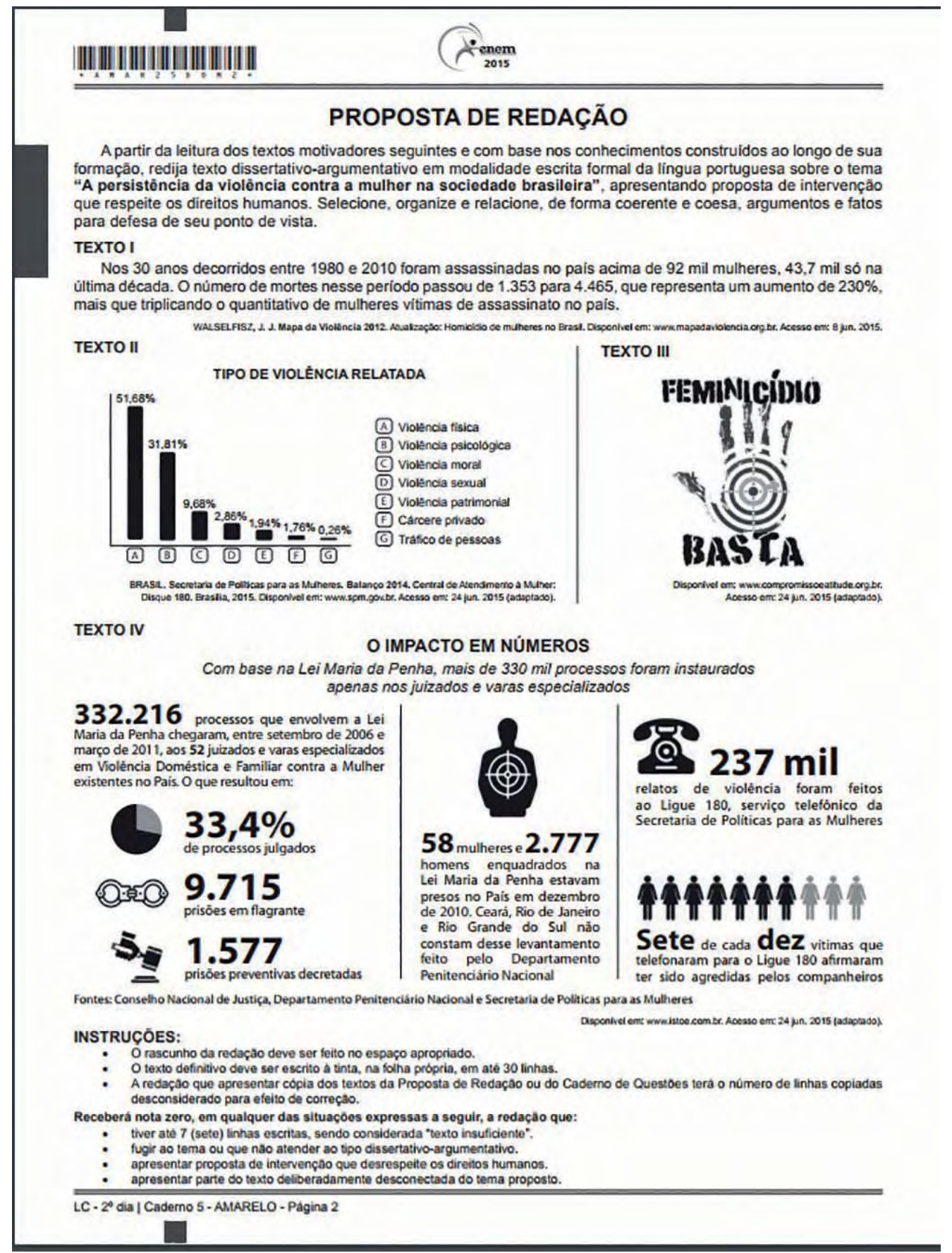

Fonte: Brasil (2015). 
Nesta etapa de reconhecimento, o professor deve contextualizar as informações sobre os textos projetados, explicando que o primeiro se trata de um espelho da prova de redação fornecido pelo Inep na página do candidato após o período de correção e divulgação da nota dos participantes do exame e o segundo corresponde à prova em si, mas não se deve divulgar a nota conferida ao texto. Estas ações estão associadas simultaneamente à etapa de pesquisa do gênero, pois a amostra sugerida já constitui um parâmetro consistente para a atividade de produção, todavia, ela deve ser ampliada paralelamente à atividade de leitura de textos do gênero. Pensar a leitura no ambiente escolar requer um trabalho que não se preocupe apenas com o conhecimento do código linguístico. Ler ultrapassa esse limite quando nos dispomos a trabalhar a língua nas dimensões social e dialógica (COSTA-HÜBES; SIMIONI, 2014, p. 29).

Os alunos devem realizar a leitura silenciosa dos textos, disponibilizados por meio de cópias individuais. Após a leitura, a atenção da turma deve ser retomada com novos questionamentos: "Algum trecho do texto chamou sua atenção? Por quê?"; "Qual nota você atribuiria a esta redação, se fosse um avaliador do Enem?". As respostas deverão ser sintetizadas em palavras-chave anotadas no quadro/lousa e socializadas. $\mathrm{Na}$ sequência, deve ser revelada a real nota do texto em questão. Esta informação também deve ser debatida pelos alunos.
Outra dissertação correspondente à prova 2015, mas esta avaliada com nota 1.000, deve ser lida individualmente. $\mathrm{O}$ texto é oriundo da Cartilha do Participante, disponibilizada na página virtual do Inep. Os mesmos questionamentos e procedimentos devem ser realizados após a leitura desse segundo texto. A ideia é possibilitar que os estudantes prossigam com mais clareza para a etapa de análise linguística.

Figura 6 - Redação extraída da Cartilha do Participante do Enem 2016

Redação de JULIA CURı AUGUSTO PEREIRA

Escola pública de Campo Grande - MS

Permeada pela desigualdade de gênero, a história brasileira deixa clara a posicäa inferior imposta a todas as mulleres Essas, mesmo após a conquista do acesso as voto, consino e trabalho - negado por seculos - permanecem vítimas da violencia, uma realidade que ceifa vidas $e$ as priva do direito a terem sua integridade física e moral protegida. O machismo c a misoginia sĩo promovidos pela própria sociedade. Meninas säo ensinadas a aclitar a submissäo as posicionamento masculino, ainda que estajam inclusas agressôes e violencia, do abuso psicológico as sexual. Os meninos, por sua vez, têm seu carater construido à medida que absorvem valores patriarcais e abusivos, os quais seräo refletidos em suas condutas ulteriores.

Um dos conceitos filosoficos de Francis Bacon, que declara o comportamento humano como contagioso, se aplica perfeitamente à situagão. A violencia de gêvero, conforme permanece a ser reproduzida, torna-se enraizada e frequente. Concomitantemente, a voz das mulheres $e$ silenciada e suas manifestaçöes são reprimidas, o que farorece o mantimento das atitudes misóginas.

$O$ ensino veta todo equalquer tipo de instruçäo a respecito do feminismo e da igualdade de gênero e contribui com a perpetuaģäo da ignorância e do consequente preconccito. Ademais, os veiculos de comunicactas pouco abordam a temática, enquanto o Estado colabora com a Lei Maria da Penha, nem sempre eficaz, e com unidades da Delegacia da Mulher, em nimero insuficiente.

Entende-se, diante do exposto, a real necessidade de açäes governamentais que garantam que a lei puna todos os tipos de violéncia, além da instalaçäo de delegacias especificas em áreas necessitadas. Cabe à sociedade, em parceria com a midia e com as escolas, instrucöes sobre igualdade de gênero e campanhas de oposiçĩo à violéncia contra as mulheres. Essas, por fim, devem permanecer unidas, atraves do feminismo, em busca da garantia de seus direitos básicos e seu bem-estar social.

Fonte: Brasil (2016).

Então, a progressão segue para a análise linguística. As propostas de análise linguística "destacam atividades 
contextualizadas que propiciem ao aluno refletir sobre organização da língua em seu uso efetivo, ou seja, estudá-la em seu funcionamento" (COSTA HÜBES; SIMIONI, 2014, p. 31). A análise linguística pode ser contextualizada pelo comentário dos avaliadores constante na cartilha, que também será lido, porém, em conjunto, acompanhando projeção ou impressão individual. A ideia, como já dito, é apresentar encaminhamentos para a análise, pois esta etapa pode ser retomada ao longo da sequência completa de produção escrita.

Antunes (2007) discorre que a língua é constituída por um léxico e uma gramática: o léxico diz respeito ao vocabulário da língua e a gramática corresponde às regras que a constituem. Logo, estudar a estrutura linguística implica considerar as situações de interação e, por sua vez, os recursos de textualização que proporcionam a tessitura do texto. As possibilidades de condução da atividade de análise linguística são muitas,

[...] à medida que possibilita ao aluno uma análise sociológica das condições de produção do enunciado e contribui para que se perceba elementos organizadores das sequências discursivas que compõem um gênero (COSTA-HÜBES; SIMIONI, 2014, p. 32).

Por isso, justifica-se uma atividade de análise inicial conforme os moldes da análise linguística do gênero dissertação argumentativa no Enem, sintetizada pelos comentários da Cartilha do Participante. Trata-se de uma questão de conciliar os objetivos de apreensão da dimensão científica do gênero com vistas à sua situação social de comunicação, considerando que o Enem constitui uma prescrição de grande importância para os aprendizes e, subjetivamente, também para o trabalho docente.

A análise linguística conduzida pela Matriz de Referência da Redação do Enem é norteada pela apreciação de cinco competências: I- demonstrar domínio da norma padrão da língua escrita; II- compreender a proposta de redação e aplicar conceitos das várias áreas de conhecimento para desenvolver o tema, dentro dos limites estruturais do texto dissertativo-argumentativo; III- selecionar, relacionar, organizar e interpretar informações, fatos, opiniões e argumentos em defesa de um ponto de vista; IV- demonstrar conhecimento dos mecanismos linguísticos necessários para a construção da argumentação; e V- elaborar proposta de solução para o problema abordado, respeitando os valores humanos e considerando a diversidade sociocultural. Na cartilha do participante, as competências da Matriz de Referência são traduzidas em comentários, conforme Figura 7: 
Figura 7 - Comentário sobre a redação de Júlia Pereira, da escola pública de Campo Grande, MS, extraído da Cartilha do Participante do Enem 2016

\footnotetext{
Comentário

A participante demonstra que tem excelente domínio da modalidade escrita formal da Lingua Portuguesa tanto pelas estruturas linguisticas construidas como pela seleçāo lexical e pela escolha de registro. Não há erros de convençōes da escrita. Como única inadequaçăo, aponta-se, no terceiro parágrafo, o emprego do verbo permanecer ( $\mathrm{em}$ vez de continuat), no trecho "conforme permanece a ser reproduzida".

A redaça esta estruturada em cinco parágrafos, nos quais s3̃o organizados blocos temáticos independentes, mas bern articulados entre si.

O tema proposto no enunciado da prova é bem desenvolvido pela participante, por meio de argumentação consistente, fundamentada em repertório sociocultural produtivo, uma vez que cita Francis Bacon, extrapola as ideias apresentadas nos textos motivadores e focaliza a natureza machista e patriarcal da sociedade brasileira. Apresenta também excelente domínio do texto dissertativo-argumentativo, corn introduçăo, desenvolvimento e conclusảo. 0 tema se desenvolve de modo fluente e articulado ao ponto de vista defendido, configurando autoria. Em defesa de seu ponto de vista, a texto apresenta informaçōes relacionadas ao papel da educaçăo e dos veículos de comunicaçăo na construçăo da desigualdade entre os gêneros e do preconceito contra a mulher.

A redaçāo apresenta encadeamento entre as ideias e a participante demonstra competência em selecionar, relacionar, organizar e interpretar informaçōes, fatos e argumentos em defesa de um ponto de vista: o tema é desenvolvido de forma coerente. os argumentos selecionados săo consistentes e a conclusão é relacionada ao ponto de vista adotado.

Além de assegurar a continuidade $e$ a progressividade temáticas, o texto articula, sem inadequaçōes, repertório diversificado de recursos coesivos, que concatenarn as informaçōes apresentadas, como "Essas" (1" paragrafo); "ainda que", "por sua vez", "os quais" (2" parágrafo) "se aplica perfeitamente à situaçăo", "o que" (3" parágrafo); "Adernais" (4" parágrafo); "diante do exposto", "além", "Essas" (5" parágrafo).

Ao elaborar sua excelente proposta de intervençăo, que respeita os direitos humanos, a participante considera que são necessárias açōes governamentais, como a multiplicaçăo de delegacias especiais de atendimento à mulher, $\mathrm{e}$ a̧̧ōes da sociedade, dos meios midiáticos $\mathrm{e}$ do sistema educacional em campanhas de oposiç̧̄o à violência contra as mulheres. A proposta de intervençăo relaciona-se ao tema e resulta da discussåo desenvolvida no texto, além de ser abrangente, bem elaborada $e$ bem detalhada.
}

Fonte: Brasil (2016).

O exemplo deste comentário deve constituir um roteiro para a atividade de leitura e avaliação. Os estudantes serão instruídos a retornar à leitura da primeira dissertação apresentada - "O que uma canção continua a ensinar sobre a violência" - e, em grupos pequenos, discutir e sistematizar um comentário sobre o texto. Os comentários serão socializados com a turma por meio de exposição oral de cada grupo. É interessante salientar que o intuito dessa atividade não é avaliar se os estudantes já possuem pleno domínio de todas as habilidades preconizadas pela Matriz de Referência, mas identificar como interpretam os termos-chave presentes no comentário extraído da cartilha (domínio da modalidade da escrita formal em Língua Portuguesa, argumentação consistente, domínio do texto dissertativo-argumentativo, selecionar, relacionar, organizar e interpretar informações, fatos e argumentos em defesa de um ponto de vista, repertório diversificado de recursos coesivos e proposta de intervenção que respeite os direitos humanos) e realizar um diagnóstico que possa direcionar a continuidade da transposição didática do gênero. Espera-se que, a partir da sistematização e da oralização da interpretação desses conceitos, o professor angarie subsídios para desenvolver uma análise que presentifique aspectos salutares do gênero. Essa atividade precede a última prevista pelo módulo de reconhecimento, que consiste em conjugar as contribuições dos alunos com apontamentos sobre o texto avaliado por eles. Algumas observações podem compor um roteiro para o professor:

- Argumentação - introdução $\left(1^{\circ}\right.$ e $2^{\circ}$ parágrafos) - argumento utilizado pelo autor: violência contra a mulher é uma realidade e a violência psicológica agrava os processos de violência.

- Estratégias argumentativas:

$\rightarrow$ canção de Chico Buarque retrata a complexidade dos processos de violência contra a mulher;

$\rightarrow$ violência psicológica é velada (transforma a vítima em culpa- 
da) e se relaciona com as demais violências.

- Conclusão ( $6^{\circ}$ e $7^{\circ}$ parágrafos):

$\rightarrow$ proposta de intervenção: é necessário garantir direito de escolha às mulheres;

$\rightarrow$ união de causa é a chave para aprimorar e cumprir a legislação de proteção à mulher;

$\rightarrow$ falta de engajamento perpetuará o ciclo da violência.

- Observação: o texto perdeu ritmo na conclusão, apresentando proposta de intervenção relacionada ao tema, mas pouco articulada à discussão desenvolvida no texto, acarretando em penalização na nota.

Realizadas as discussões, cabe ao docente avaliar o direcionamento das tarefas conseguintes. É possível solicitar produção inicial ou um novo encadeamento de atividades correspondente a uma tangente específica da análise linguística. As atividades de reescrita e a preocupação com a circulação social do gênero não podem ser negligenciadas.

\section{Considerações finais}

Nitidamente, nenhuma proposta didática deve ser encarada de forma estanque. No âmbito do ensino da Língua Portuguesa pautado pelo trabalho com gêneros textuais, a afirmação é ainda mais latente, pois é sua própria orientação dialógica que de fato aponta encaminhamentos, porém, também compreende que é da interação que emergem novos caminhos. Portanto, a intenção deste trabalho é constituir um ponto de partida, e não um mapa infalível.

Nesta linha, justifica-se a preocupação em apresentar propostas de atividades que contemplem o módulo de reconhecimento do gênero dissertação argumentativa, afinal, sua relevância para o ensino médio brasileiro exige uma modelização que permita que ele seja desenvolvido pelos aprendizes de forma coerente e que promova desenvolvimento. Logo, a adoção da adaptação da sequência didática postulada por Costa-Hübes e Swiderski (2009), em etapas de apresentação da situação de comunicação, seleção do gênero/discurso textual, reconhecimento do gênero, produção oral ou escrita, reescrita do texto e circulação, constitui uma proposta metodológica possível e fértil para professores e estudantes. Cada etapa não se encerra em si, mas é resgatada e reconfigurada na medida em que constrói uma memória didática que se soma ao tão buscado processo de internalização do conhecimento.

Acredita-se que os objetivos de situar o conteúdo socialmente e despertar debates e inquietações serão alcançados na medida em que se multiplicar a consciência quanto à exigência de tarefas e dispositivos didáticos específicos para se estimular a atmosfera propícia à aprendizagem. Nesse contexto, a presentificação do objeto de ensino pautada em seu reconhecimento a partir de pesquisa, leitura e análise linguística merecem atenção redobrada, pois estas são as etapas responsáveis pela organização do 
trabalho pedagógico e pelo envolvimento dos alunos.

A mediação pedagógica é traduzida em um amálgama da mediação pela linguagem, e ambas se complementam neste processo que busca a transformação de seus atores, na medida em que desenvolvem suas capacidades - de ação, discursiva e linguístico-discursiva - e realizam a tomada de consciência quanto às suas ações em um processo de síntese do desenvolvimento.

\section{Genre recognition module: Enem's dissertation argumentative from an interactionist perspective}

\begin{abstract}
This paper presents reflections and possibilities related to genre recognition module in didactical modelling of teaching object in argumentative-dissertation in High School under the patterns of appreciated genre in High School National Exam (HSNE). Therefore, it presents a literature review which explains the presentification of the teaching object, which corresponds to this recognition modelling. The epistemological course comprehends the interacionist concept of human development mediated and observed by language, based on Vygotsky and Bakhtin premises, from sociodiscursive interactionism in what regards to didactical transposition and oriented documents, as the Referential Matrices of Essay in Enem and the Participant Booklet, in which it relates to the researched
\end{abstract}

genre characterization. As a result of the observations, it is presented a productive methodological proposal to teachers and students in High School in relation to the argumentative- dissertating textual genre in Enem.

Keywords: Teaching. Language. Portuguese.

\section{Referências}

ANTUNES, Irandé. Muito além da gramáti$c a$ : por um ensino de línguas sem pedras no caminho. São Paulo: Parábola, 2007.

BAKHTIN, Mikhail. Os gêneros do discurso. In: ___ Estética da criação verbal. 2. ed. São Paulo: Martins Fontes, 1997. p. 277-289. . Problemas da poética de Dostoiévski. Tradução de Paulo Bezerra. 5. ed. Rio de Janeiro: Forense Universitária, 2010.

BRASIL. Ministério da Educação. A redação do Enem. Brasília: Inep, 2011. Disponível em: $<$ http://download.inep.gov.br/educacao_basica/enem/downloads/2011/a-redacao-do-enem-2011.pdf >. Acesso em: 25 jul. 2017.

. Ministério da Educação. Espelho de redação. Brasília: Inep, 2015. Disponível em: <http://www.inep.gov.br/>. Acesso em: 9 jan. 2016.

. Ministério da Educação. Redação do Enem 2016: cartilha do participante. Brasília: Inep, 2016. Disponível em: <http:// download.inep.gov.br/educacao_basica/enem/ guia_participante/2016/manual_de_redacao_ do_enem_2016.pdf >. Acesso em: 25 jul. 2017.

BRONCKART, Jean-Paul. Atividade de linguagem, discurso e desenvolvimento humano. São Paulo: Mercado das Letras, 2006.

COSTA-HÜBES, Terezinha da Conceição; SIMIONI, Claudete Aparecida. Sequência didática: uma proposta metodológica curricular de trabalho com os gêneros discursivos/textuais. In: BARROS, Eliana Merlin Deganutti 
de; RIOS-REGISTRO, Eliane Segati (Org.). Experiências com sequências didáticas de gêneros textuais. Campinas: Pontes, 2014. p. 15-39.

COSTA-HÜBES, Terezinha da Conceição; SWIDERSKI, Rosiane Moreira da Silva. Abordagem sociointeracionista e sequência didática: relato de uma experiência. Línguas e Letras, Cascavel, v. 10, n. 18, p. 113-128, 2009.

DOLZ, Joaquim. Por que participar?: escrever um desafio para todos. Brasília: MEC, 2014. (Cadernos Virtuais; Olimpíada de Língua Portuguesa Escrevendo o Futuro).

DOLZ, Joaquim; NOVERRAZ, Michéle; SCHNEUWLY, Bernard. Sequências didáticas para o oral e a escrita: apresentação de um procedimento. In: DOLZ, Joaquim et al. Gêneros orais e escritos na escola. Tradução de Roxane Rojo e Glaís Cordeiro. Campinas: Mercado das Letras, 2004. p. 95-118.

MACHADO, Irene. Gêneros discursivos. In: BRAIT, Beth (Org.). Bakhtin conceitos-chave. São Paulo: Contexto, 2005. p. 17-31.

MARCUSCHI, Luiz Antônio. Gêneros textuais: configuração, dinamicidade e circulação. In: KARWOSKI, Acir C.; GAYDECZKA, Bruno; BRITO, Karim Siebeneicher. Gêneros textuais: reflexões e ensino. São Paulo: Parábola, 2011. p. 17-31.

NASCIMENTO, Elvira Lopes; BRUN, Edna Pagliari. Transposição didática e gestos profissionais de ensinar: a construção do objeto de ensino pelo professor de língua portuguesa. Linguagem em (Dis)curso, Tubarão, 2017. No prelo.

NASCIMENTO, Elvira Lopes; PEREIRA, Liliane. Mediação: instrumentos semióticos para aprendizagens e desenvolvimento. In: BARROS, Eliana Merlin Deganutti de; RIOS-REGISTRO, Eliane Segati (Org.). Experiências com sequências didáticas de gêneros textuais. Campinas: Pontes, 2014. p. 97-124.
OLIVEIRA, Marta Kohl de. Vygotsky aprendizado e desenvolvimento: um processo sócio-histórico. São Paulo: Scipione, 1993.

VYGOTSKY, Lev Semenovitch. Linguagem e pensamento. Ebooks Brasil. Copyright: setembro de 2001. Disponível em: <http:// www.ebooksbrasil.org/eLibris/vigo.html>. Acesso em: 25 jul. 2017. 